\title{
Diagnostic Performance of a Novel Multiplex Immunoassay in Colorectal Cancer
}

\author{
KATJA DRESSEN $^{1}$, NATALIE HERMANN ${ }^{1}$, STEFFEN MANEKELLER ${ }^{2,3}$, \\ GISELA WALGENBACH-BRUENAGEL ${ }^{2,3}$, FRANK A. SCHILDBERG ${ }^{4}$, KARINA HETTWER $^{5,6}$, \\ STEFFEN UHLIG ${ }^{5,6}$, JÖRG C. KALFF ${ }^{2,3}$, GUNTHER HARTMANN ${ }^{1,3}$ and STEFAN HOLDENRIEDER ${ }^{1,3,6}$ \\ ${ }^{1}$ Institute of Clinical Chemistry and Clinical Pharmacology, University Hospital Bonn, Bonn, Germany; \\ ${ }^{2}$ Department of Surgery, University Hospital Bonn, Bonn, Germany; \\ ${ }^{3}$ Center for Integrated Oncology (CIO), Köln/Bonn, Bonn, Germany; \\ ${ }^{4}$ Institutes of Molecular Medicine and Experimental Immunology, University Hospital Bonn, Bonn, Germany; \\ ${ }^{5}$ QuoData Statistics GmbH, Dresden, Germany; \\ ${ }^{6}$ Joint Research and Services Center for Biomarker Evaluation in Oncology, Bonn/Dresden, Germany
}

\begin{abstract}
Background/Aim: We evaluated the diagnostic performance of a newly-launched magnetic bead-based multiplex immunoassay panel including cancer, apoptotic, immunological and angiogenesis biomarkers for differential diagnosis of colorectal cancer (CRC). Patients and Methods: Serum samples of 106 individuals comprising of 35 patients with CRC (23 colon cancer, 12 rectal cancer), 20 with respective benign colorectal diseases and 51 healthy controls were analyzed by the Milliplex ${ }^{T M}$ MAP Human Circulating Cancer Biomarker Panel 1 run on the Bio-Plex ${ }^{T M} 200$ System. Results: IL-8, CEA, HGF, TNF $\alpha, C Y F R A$ 21-1, OPN, TGFa, CA 19-9, CA 125, AFP and sFas showed significantly higher levels in cancer samples compared to healthy controls. It is noteworthy that comparing CRC and benign colorectal disease samples, many immunological and cell death markers were elevated as well. Exclusively, six markers were distinguished significantly between both groups: CEA showed the best performance in differential diagnosis reaching an AUC of 0.859 in ROC curve followed by CA 19-9, CYFRA 21-1, IL-8, CA 125 and OPN reaching $A U C s$ between 0.696 and 0.744. Correlation with tumor stage was found for CEA, sFas and CYFRA 21-1. Finally marker scores were assembled showing that a combination of CEA and CA 19-9 had a higher AUC (0.893) compared to
\end{abstract}

Correspondence to: Stefan Holdenrieder, MD, Institute of Clinical Chemistry and Clinical Pharmacology, University Hospital Bonn, Sigmund-Freud-Str. 25, D-53127 Bonn, Germany. Tel: +49 22828712126, Fax: +49 22828712159, e-mail: Stefan.Holdenrieder@ uni-bonn.de

Key Words: Colorectal cancer, biomarker, multiplex immunoassay, tumor marker, CEA, CA 19-9, IL-8. the biomarkers alone. Conclusion: Differential diagnosis of CRC can be improved by new biomarker classes and their combination assessed by novel multiplex immunoassay.

Colorectal cancer (CRC) is one of the most common cancers worldwide. With an estimated incidence of 447,000 new cases and 215,000 cancer related deaths in 2012, it is the second most common cancer in Europe (1). However, the treatability of CRC has been improved over the last decades resulting in a relative 5-year survival of $66.1 \%$ in 2005-2011 compared to only $49.8 \%$ in $1975-1977$ (2). Especially the implementation of more efficient adjuvant chemotherapies in stage II-III CRC in the 1990s had a great impact by increasing the prognosis in these stages up to a mean 5-year survival of $66 \%$ (3). In the last decade, neoadjuvant and radiochemo-therapeutic regimes, as well as targeted therapies led to a further decrease of death rates of approximately $3 \%$ per year (4). But still only slightly more than $10 \%$ will survive a stage IV cancer more than 5 years $(5,6)$.

Screening programs for early diagnosis of CRC have been implemented in many western countries. In particular, colonoscopy and (immunochemical) fecal occult blood testing (FOBT and FIT) have demonstrated to decrease CRC-associated mortality (7-9). However, colonoscopy is an invasive procedure; therefore only a small percentage of individuals at-risk is willing to undergo this exam (10). FOBT is non-invasive, cost-efficient and well validated (LOE 1a) but it is limited by its low sensitivity for CRC $(<50 \%)$ - especially for adenomas and early stage cancers and its low specificity (11). The fecal immunochemical test (FIT) provides considerable advantages with its higher accuracy $(7,8)$. While screening programs have significantly reduced cancer mortality, still nearly half of CRCs are diagnosed at advanced stages III or IV $(12,13)$. 
In contrast to screening in asymptomatic individuals, differential diagnosis approaches become relevant in patients presenting with specific cancer-related signs or symptoms. Markers should be sensitive, tumor- and organ-specific, distinguish malignant from benign lesions and correlate with tumor stage and prognosis (14). For both settings, bloodbased biomarkers are promising diagnostic tools as they are easily obtained, robust, cost-efficient and mirror biochemical cancer characteristics. But still serum biomarkers are not recognized as relevant tools in cancer detection and definitive diagnosis of colorectal cancer is still done by imaging and histopathological assessment (14). Although discovered more than 50 years ago (15), carcinoembryogenic antigen (CEA) is the only marker recommended for supporting diagnosis and therapy monitoring by different societies like the National Academy of Clinical Biochemistry (NACB) (16), the European Group on Tumor Markers (EGTM) (17) and the American Society of Clinical Oncology (ASCO) (16).

Accuracy of cancer detection can be improved by assembling oncological and other biomarkers in patterns as already seen in CRC and other cancers (18-20). As development and progression of cancer disease is considered a complex process involving diverse cell death, proliferation and growth pathways, as well as an interaction with the tumor microenvironment and immunological reactions of the host, biomarkers reflecting these aspects are promising candidates for these panels (21-23).

A newly-launched Human Circulating Cancer Biomarker Multiplex Immunoassay enables parallel biomarker measurements and gives the possibility to depict this complex and dynamic interaction with the promise of being a faster, less volume wasting and more inexpensive tool (23). It comprises a widespread spectrum of established tumor markers such as CEA and cancer antigen 19-9 (CA 19-9), upcoming auspicious oncological markers as cytokeratin 19fragments (CYFRA 21-1), soluble cell death markers sFas, its ligand sFasL and the tumor necrosis factor related apoptosis-inducing ligand (TRAIL), the angiogenetic marker vascular endothelial growth factor (VEGF) and immunological biomarkers like the growth proliferating cytokine stem cell factor (SCF), the interleukines 6 (IL-6) and 8 (IL-8), the macrophage migration inhibitory factor (MIF) and the tumor necrosis factor alpha (TNF $\alpha)$ (24-32).

Until now, there are no guidelines for multiplex assay configuration and implementation of these assays into clinical routine diagnostics failed due to technical and operational challenges (33). Many assays are for researchuse-only (RUO) with not declared reagent stability that prevails high-quality in vitro diagnostic. Further problems are possible cross-reactivity and validation of these assays only in small clinical studies $(34,35)$.

As a first step of assay evaluation, we assessed the methodical quality and pre-analytical robustness of the cancer biomarker multiplex assay and found a good performance for most markers (36). On this steady bedrock we performed a clinical investigation testing the relevance of the included biomarkers for differential diagnosis in CRC and their correlation with clinical cancer characteristics.

Finally, we investigated marker combination scores including the best performing biomarkers to improve the sensitivity and specificity over those reached by CEA alone in clinical routine measurements.

\section{Materials and Methods}

Subjects and sample collection. Serum was collected from 106 individuals comprising of 35 patients with colorectal cancer (23 colon and 12 rectal cancer), 20 with respective benign colorectal diseases and 51 healthy controls. Among cancer patients, 21 had metastatic and 14 non-metastatic disease (one patient with TIS) (Table I).

Samples were taken at time of cancer disease before surgery or chemotherapy was performed. As the relevant control group, samples of patients suffering from benign colorectal diseases, e.g. chronic diseases like polyposis syndromes, non-hereditary polyps, inflammatory diseases like chronic or acute diverticulitis and colitis ulcerosa were included. In addition, serum of 15 male and 36 female healthy individuals was considered as control group. Pregnant women were excluded as well as persons with a cancer history. The study was approved by the Ethics Committee of the Medical Faculty of the University of Bonn (Nr. 319/12) and informed consent was obtained from study participants.

The patient sera were collected prospectively in the Department of Surgery and other Clinics of the Center of Integrated Oncology (CIO) Köln/Bonn at the University Hospital Bonn between 2010 and 2012. Transport, handling and storage of the samples were done in a standardized way in the Biofluid Biobank of University Hospital Bonn. In particular, blood was centrifuged at $3300 \mathrm{~g}$ for $10 \mathrm{~min}$, aliquoted in polypropylene tubes and stored at $-80^{\circ} \mathrm{C}$ until use. The history of every patient was thoroughly filed and information was stored pseudonymised.

Multiplex immunoassay. To determine biomarker concentrations, all samples were measured by use of the MILLIPLEX ${ }^{\mathrm{TM}}$ MAP Human Circulating Cancer Biomarker Magnetic Bead Panel 1, 96 Well Plate Assay, Cat. \# HCCBP1MAG-58K (Merck Millipore, Billerica, MA) run on the Bio-Plex ${ }^{\mathrm{TM}} 200$ system (Bio-Rad, Hercules, CA). Quality controls (QC1 and QC2), as well as a calibration curve based on 1:3 dilutions of the highest standard were used for quantification and as internal controls for intra- and inter-assay reproducibility. In addition, serum pools, produced as previously described, were used as external physiological controls (36). The detailed method and procedure are reported in Hermann et al. (36). Roughly summarized, it is a magnetic bead suspension multiplex assay methodologically based on flow cytometry.

In every bead, two fluorescent dyes are set, whose proportion to each other creates 100 distinguishable possibilities. On beads with identical characteristics a capture antibody is fixed covalently. The analyzed panel includes 24 biomarkers: the oncological biomarkers carcinoembryonic antigen (CEA), alpha-fetoprotein (AFP), total prostate-specific antigen (total-PSA), cancer antigen 15-3 (CA 15-3), cancer antigen 19-9 (CA 19-9), cancer antigen 125 (CA 125), 
Table I. Patient characteristics.

\begin{tabular}{lccccc}
\hline Group & Total & Male & Female & Median age & (range) years \\
\hline Healthy controls & 51 & 15 & 36 & 39.4 & $(20.1-78.1)$ \\
Benign colorectal disease & 20 & 8 & 12 & 54.7 & $(24.2-89.8)$ \\
$\quad$ Colon & 18 & 8 & 10 & 56.3 & $(24.2-89.8)$ \\
$\quad$ Rectum & 2 & 0 & 2 & 42.6 & $(39.4-46.0)$ \\
Colorectal cancer & 35 & 22 & 13 & 69.4 & $(19.6-86.3)$ \\
$\quad$ Colon & 23 & 13 & 10 & 68.0 & $(19.6-80.0)$ \\
Rectum & 12 & 9 & 3 & 74.2 & $(46.0-86.3)$ \\
UICC stage & 1 & 1 & 1 & 51.0 & $(47.8-61.5)$ \\
$\quad 0$ & 3 & 2 & 2 & 70.5 & $(57.7-73.7)$ \\
$\quad$ I & 5 & 3 & 2 & 73.5 & $(68.1-82.0)$ \\
$\quad$ II & 5 & 13 & 8 & & $(63.7-79.9)$ \\
$\quad$ III & 21 & & &
\end{tabular}

cytokeratin 19-fragments (CYFRA 21-1), $\beta$-human chorionic gonadotropin $(\beta-\mathrm{HCG})$, human epididymis protein 4 (HE4), osteopontin (OPN), prolactin, the cell death and angiogenesis markers soluble Fas (sFas), soluble Fas-ligand (sFasL), tumor necrosis factor related apoptosis-inducing ligand (TRAIL), vascular endothelial growth factor (VEGF) as well as the immunological markers interleukin-6 (IL-6), interleukin-8 (IL-8), tumor necrosis factor- $\alpha$ $(\mathrm{TNF} \alpha)$, transforming growth factor- $\alpha(\mathrm{TGF} \alpha)$, fibroblast growth factor-2 (FGF2), macrophage migration inhibitory factor (MIF), leptin, hepatocyte growth factor (HGF) and stem cell factor (SCF). Beads were pre-mixed and given into the wells containing diluted serum and reagents. After overnight incubation and fixation of the antigen (e.g. CEA) on the capture antibody linked to the magnetic microsphere, a biotinylated detection antibody was added. As reporter molecule streptavidin-phycoerythrin (PE) conjugate is introduced binding the biotinylated detection antibodies and completing the reaction. Finally two lasers interrogated the microspheres fast passing through the system. The first laser excites the discrete internal dye of the bead identifying the specific antibody and the other one the reporter molecule PE and thereby quantifying the result.

Statistical analysis. Biomarker levels between colorectal cancer patients and healthy controls were compared, as well as between colorectal cancer patients and patients with benign colorectal diseases. Log-transformation of biomarker levels was done for variance stabilization. For significance testing $t$-test was used or, when data were not following a normal distribution, Wilcoxon rank sum test. The significance level was adjusted to $p \leq 0.001$ following a Bonferroni correction for multiple testing. Then, areas under the curve (AUC) of receiver operating characteristic (ROC) curves and sensitivities of relevant biomarkers at $95 \%$ specificity versus the control group were calculated. The combination of significantly discriminating biomarkers was analyzed by a logistic regression approach.

\section{Results}

Markers that significantly discriminated between patients with colorectal cancer and healthy controls were IL-8, CEA, HGF, TNF $\alpha$, CYFRA 21-1, OPN, TGF $\alpha$, CA 19-9, CA 125,
AFP and sFas ( $p$-values $\leq 0.001$, markers ordered according $p$-values). For all markers higher values were observed in cancer patients than in healthy controls. Other markers had a tendency to higher values in cancer patients as well, however the level of significance ranged between 0.05 and 0.001 . Details are listed in Table II and an overview is given as a heat map in Figure 1 (Figure 1, Table II).

When comparing colorectal cancer and benign colorectal diseases the established biomarker CEA and additionally IL-8 were the only markers with significant differences $(p \leq 0.001)$. Median concentration of CEA was $6.7 \mathrm{ng} / \mathrm{ml}$ (range: 0.4-150.0 $\mathrm{ng} / \mathrm{ml}$ ) in patients with cancerous lesions compared to 1.1 $\mathrm{ng} / \mathrm{ml}(0.3-4.2 \mathrm{ng} / \mathrm{ml})$ in those with benign colorectal diseases and $0.5 \mathrm{ng} / \mathrm{ml}(0.1-13.6 \mathrm{ng} / \mathrm{ml})$ in healthy controls. Median level of IL-8 in cancer patients was $17.9 \mathrm{pg} / \mathrm{ml}(6.3-169.5$ $\mathrm{pg} / \mathrm{ml})$ whereas in benign colorectal diseases a value of 10.1 $\mathrm{pg} / \mathrm{ml}(5.0-28.5 \mathrm{pg} / \mathrm{ml})$ and in healthy controls a value of 5.0 $\mathrm{pg} / \mathrm{ml}$ (5.0-30.7 pg/ml) was observed. CA 19-9, CYFRA 21-1, CA 125, OPN and CA 15-3 reached significance levels between 0.05 and 0.001 for the discrimination between malignant and benign colorectal diseases (Figure 2, Table II).

Concerning the stage-dependency between nonmetastasized and metastasized colorectal lesions, several markers had higher levels in advanced stages, CEA achieved the best performance $(p=0.0001)$ followed by the cell death marker sFas $(p=0.0007)$ and by CYFRA 21-1 $(p=0.0009)$. Markers with lower significance levels $(0.001<p<0.05)$ were CA 19-9, CA125, IL-8, prolactin and OPN (Table III).

Correlations between clinical relevant markers with correlation coefficients $\mathrm{R}>0.6$ were observed for the comparisons of CEA/IL-8 ( $\mathrm{R}=0.638), \mathrm{CEA} / \mathrm{OPN}(\mathrm{R}=0.607)$, IL-8/TNF $\alpha \quad(\mathrm{R}=0.728), \mathrm{IL}-8 / \mathrm{TGF} \alpha(\mathrm{R}=0.652), \mathrm{IL}-8 / \mathrm{HGF}$ $(\mathrm{R}=0.621), \quad \mathrm{IL}-8 / \mathrm{CYFRA} \quad 21-1 \quad(\mathrm{R}=0.621), \quad \mathrm{OPN} / \mathrm{sFas}$ $(\mathrm{R}=0.691)$, OPN/HGF $(\mathrm{R}=0.681), \mathrm{TGF} \alpha / \mathrm{TNF} \alpha(\mathrm{R}=0.683)$, TGF $\alpha / C Y F R A ~ 21-1(R=0.616)$, and TGF $\alpha / H G F(R=0.604)$. 


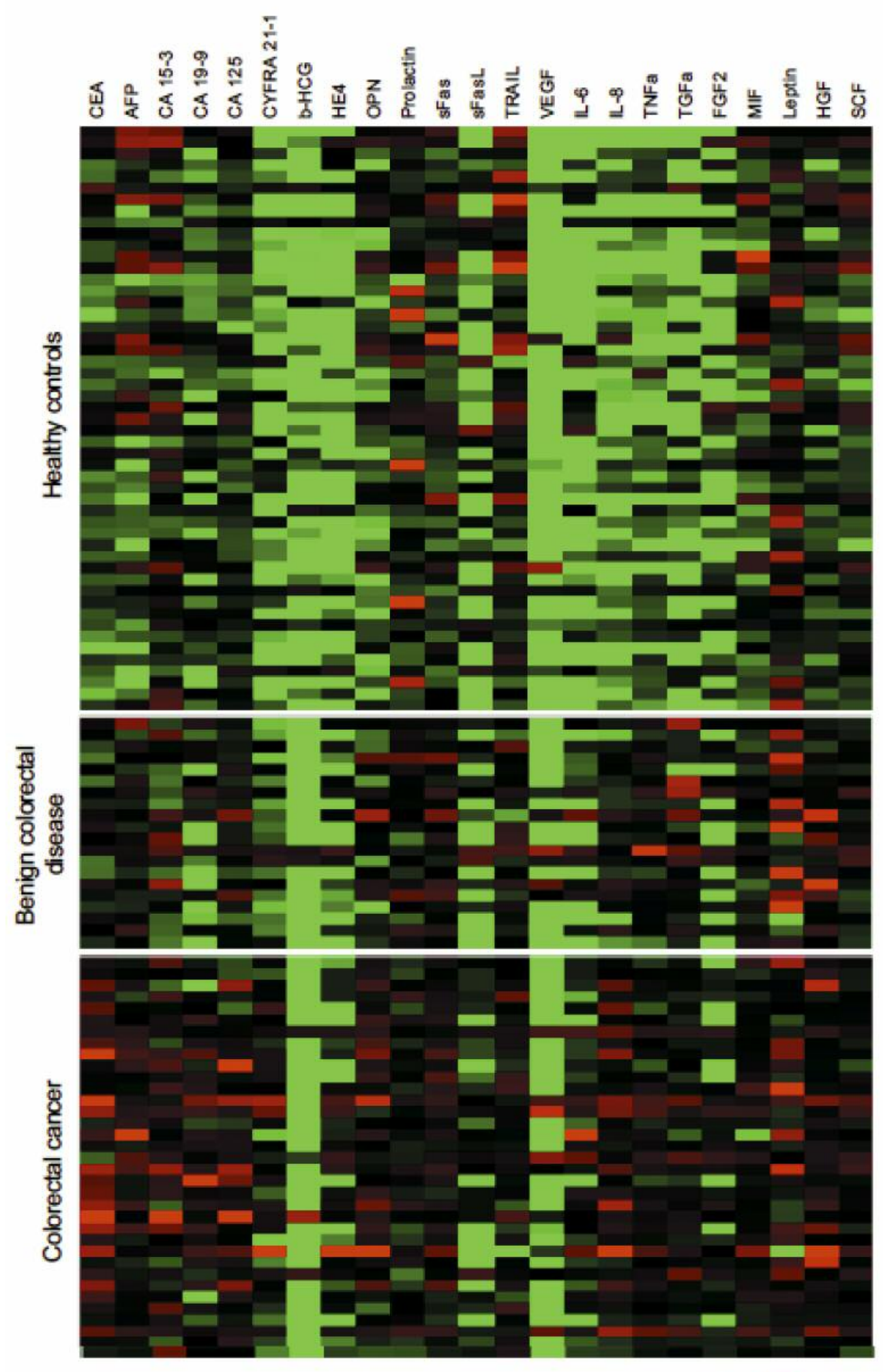

Low- -High

Figure 1. Heat maps illustrate marker levels in all sera of healthy controls, patients with benign colorectal disease and colorectal cancer. Color changes from low to high levels range from bright green, dark green, black, dark red and bright red visualizing the marker level trends in the various groups. 

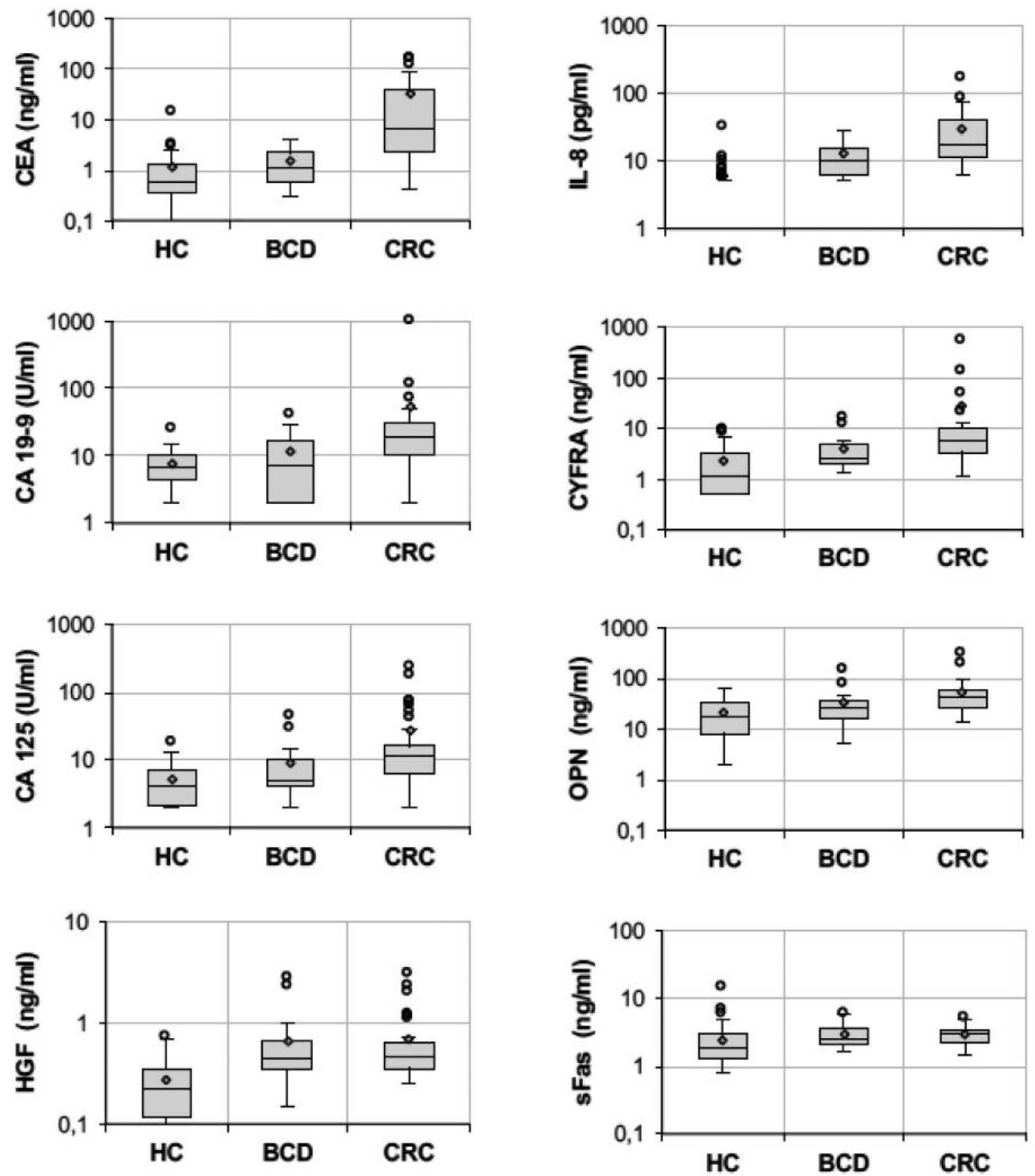

Figure 2. Box plots show marker distribution in various diagnostic groups. Box plots for biomarkers CEA, IL-8, CA 19-9, CYFRA 21-1, CA 125, $O P N, H G F$ and sFas indicate medians, means, interquartile ranges, whiskers and outliers for the groups of healthy individuals, patients with benign and malignant colorectal disease.

The power of discrimination between groups is best described by ROC curves and sensitivities at a defined specificity. For the comparison between patients with colorectal cancer and healthy controls, IL- 8 showed the best performance with an AUC of 0.976 in ROC curves and a sensitivity of $85.7 \%$ at $95 \%$ specificity followed by CEA with an AUC of 0.915 and a sensitivity of $68.8 \%$ at $95 \%$ specificity. TNF $\alpha$ had an AUC of 0.892 and a sensitivity of $80.0 \%$ while CA $19-9$ had an AUC of 0.841 and a sensitivity of $60.0 \%$ at $95 \%$ specificity. 
Table II. Biomarker concentration for each tested marker and subgroup as well as discriminative power in the intergroup comparison.

\begin{tabular}{|c|c|c|c|c|c|c|c|c|c|}
\hline \multirow{2}{*}{$\begin{array}{l}\text { Biomarker } \\
\text { Oncological biomarkers }\end{array}$} & \multirow[t]{2}{*}{ Unit } & \multicolumn{2}{|c|}{ Healthy controls } & \multicolumn{2}{|c|}{$\begin{array}{c}\text { Benign colorectal } \\
\text { diseases }\end{array}$} & \multicolumn{2}{|c|}{ Colorectal cancer } & \multirow[t]{2}{*}{$\begin{array}{c}\mathrm{HC} v s \\
\mathrm{CRC}\end{array}$} & \multirow[t]{2}{*}{$\begin{array}{c}\text { BCD vs } \\
\text { CRC }\end{array}$} \\
\hline & & & & & & & & & \\
\hline CEA & $\mathrm{ng} / \mathrm{ml}$ & 0.5 & $(0.1-13.6)$ & 1.1 & $(0.3-4.2)$ & 6.7 & $(0.4-150.0)$ & $p<0.001$ & $p<0.001$ \\
\hline AFP & $\mathrm{ng} / \mathrm{ml}$ & 1.1 & $(0.5-9.7)$ & 2.5 & $(0.9-8.1)$ & 2.6 & $(1.0-22.5)$ & $p<0.001$ & ns \\
\hline CA $15-3$ & $\mathrm{U} / \mathrm{ml}$ & 11.1 & $(2.0-36.6)$ & 8.3 & $(3.7-35.1)$ & 13.6 & $(4.8-69.0)$ & $p<0.05$ & $p<0.05$ \\
\hline CA $19-9$ & $\mathrm{U} / \mathrm{ml}$ & 6.9 & $(2-24.1)$ & 7.0 & $(2.0-38.9)$ & 19.4 & $(2.0-976.6)$ & $p<0.001$ & $p<0.05$ \\
\hline CA 125 & $\mathrm{U} / \mathrm{ml}$ & 4.0 & $(2.0-18.5)$ & 5.0 & $(2.0-43.0)$ & 11.4 & $(2-227.8)$ & $p<0.001$ & $p<0.05$ \\
\hline $\mathrm{b}-\mathrm{HCG}$ & $\mathrm{mU} / \mathrm{ml}$ & 0.2 & $(0.2-2.0)$ & 0.2 & $(0.2-2.1)$ & 0.2 & $(0.2-5.3)$ & ns & ns \\
\hline CYFRA 21-1 & $\mathrm{ng} / \mathrm{ml}$ & 1.1 & $(0.5-9.5)$ & 2.4 & $(1.3-16.5)$ & 5.6 & $(1.2-566.5)$ & $p<0.001$ & $p<0.05$ \\
\hline HE4 & $\mathrm{ng} / \mathrm{ml}$ & 2.0 & $(2.0-8.0)$ & 2.0 & $(2.0-11.0)$ & 2.6 & $(2.0-70.1)$ & $p<0.05$ & ns \\
\hline OPN & $\mathrm{ng} / \mathrm{ml}$ & 17.3 & $(2.0-63.0)$ & 26.7 & $(5.3-147.0)$ & 44.0 & $(13.1-306.5)$ & $p<0.001$ & $p<0.05$ \\
\hline Prolactin & $\mathrm{ng} / \mathrm{ml}$ & 8.4 & $(1.2-246.6)$ & 10.5 & $(3.3-37.8)$ & 9.0 & $(3.4-27.1)$ & ns & ns \\
\hline \multicolumn{10}{|c|}{ Apoptosis markers } \\
\hline sFas & $\mathrm{ng} / \mathrm{ml}$ & 1.8 & $(0.8-15.3)$ & 2.5 & $(1.7-6.0)$ & 3.0 & $(1.4-5.4)$ & $p<0.001$ & ns \\
\hline sFasL & $\mathrm{pg} / \mathrm{ml}$ & 50.0 & $(50.0-178.8)$ & 50.0 & $(50.0-111.2)$ & 50.0 & $(50.0-88.7)$ & ns & ns \\
\hline TRAIL & $\mathrm{pg} / \mathrm{ml}$ & 86.5 & $(35.8-360.9)$ & 90.0 & $(39.5-161.9)$ & 100.6 & $(25.1-172.4)$ & $\mathrm{ns}$ & ns \\
\hline \multicolumn{10}{|c|}{ Angiogenesis marker } \\
\hline VEGF & $\mathrm{pg} / \mathrm{ml}$ & 50.0 & $(50.0-743.0)$ & 50.0 & $(50.0-743.6)$ & 50.0 & $(50.0-926.1)$ & ns & ns \\
\hline \multicolumn{10}{|c|}{ Immunological markers } \\
\hline IL-6 & $\mathrm{pg} / \mathrm{ml}$ & 2.0 & $(2.0-10.2)$ & 2.0 & $(2.0-15.0)$ & 2.9 & $(2.0-61.9)$ & $p<0.05$ & ns \\
\hline IL-8 & $\mathrm{pg} / \mathrm{ml}$ & 5.0 & $(5.0-30.7)$ & 10.1 & $(5.0-28.5)$ & 17.9 & $(6.3-169.5)$ & $p<0.001$ & $p<0.001$ \\
\hline $\mathrm{TNFa}$ & $\mathrm{pg} / \mathrm{ml}$ & 5.0 & $(5.0-18.0)$ & 8.7 & $(5.0-85.1)$ & 10.2 & $(5.0-26.2)$ & $p<0.001$ & ns \\
\hline TGFa & $\mathrm{pg} / \mathrm{ml}$ & 10.0 & $(10.0-52.6)$ & 18.7 & $(10.0-122.4)$ & 18.3 & $(10.0-64.1)$ & $p<0.001$ & $\mathrm{~ns}$ \\
\hline FGF2 & $\mathrm{pg} / \mathrm{ml}$ & 50.0 & $(50.0-260.9)$ & 85.3 & $(50.0-225.6)$ & 89.9 & $(50.0-235.9)$ & $p<0.05$ & ns \\
\hline MIF & $\mathrm{ng} / \mathrm{ml}$ & 0.4 & $(0.1-13.3)$ & 0.6 & $(0.2-1.0)$ & 0.7 & $(0.1-3.5)$ & $p<0.05$ & ns \\
\hline Leptin & $\mathrm{ng} / \mathrm{ml}$ & 10.4 & $(2.9-48.8)$ & 14.2 & $(0.5-80.9)$ & 11.6 & $(0.5-76.0)$ & $\mathrm{ns}$ & ns \\
\hline HGF & $\mathrm{ng} / \mathrm{ml}$ & 0.2 & $(0.1-0.7)$ & 0.4 & $(0.2-2.7)$ & 0.5 & $(0.3-3.1)$ & $p<0.001$ & ns \\
\hline $\mathrm{SCF}$ & $\mathrm{pg} / \mathrm{ml}$ & 42.1 & $(20.0-209.6)$ & 56.5 & $(33.7-135.4)$ & 67.4 & $(31.5-152.1)$ & $p<0.05$ & $\mathrm{~ns}$ \\
\hline
\end{tabular}

Concentrations are given as median and range of the observed concentration levels, discriminative power as $p$-value of the respective intergroup comparison. Significant differences $(p<0.001)$ are highlighted in bold. Nonetheless, markers showing values between 0.05 and 0.001 are also given. HC: Healthy control, BCD: benign colorectal disease, CRC: colorectal cancer, ns: not significant.

Most relevant for differential diagnosis is the comparison between colorectal cancer and benign colorectal diseases. Here, CEA showed the best performance with an AUC of 0.859 and a sensitivity of $65.7 \%$ at $95 \%$ specificity followed by IL- 8 with an AUC of 0.744 and a sensitivity of $31.4 \%$ as well as by CA 19-9 with an AUC of 0.740 and a sensitivity of $37.1 \%$ at $95 \%$ specificity. While combination of CEA and IL-8 did not increase AUC (0.861), the combination of CEA and CA 19-9 led to an improved AUC of 0.893. Sensitivity of the marker combinations at $95 \%$ specificity were $65.7 \%$, respectively (Figure 3).

\section{Discussion}

Many efforts in diagnostic oncology aim at improving the early diagnosis of cancer and accurate differentiation between benign and malignant lesions in order to offer the most appropriate therapy options. In colorectal cancer, performance of (immunochemical) fecal occult blood test
(FOBT or FIT) and colonoscopy are well established in national screening programs as they have shown to improve colorectal cancer-related mortality (7-9). While blood-based markers are considered promising diagnostic tools, they have only rarely been recommended for cancer detection and to a greater extent for disease monitoring during and after therapy in international guidelines $(16,17)$. Although the established marker CEA was discovered more than 50 years ago (15), studies are still pending to investigate the defined use of this marker in clinical practice. Beyond oncological biomarkers, new approaches also address other markers of cell death, proliferation, interaction with the tumor microenvironment and immunological host reactions to form more meaningful marker patterns (18-23).

Recently, a multiplex immunochemical magnetic bead assay was launched as research-use-only (RUO) device that enabled the parallel assessment of 24 biomarkers involved in different pathophysiological fields of cancer development, thereby saving sample volume, analysis time, costs and 


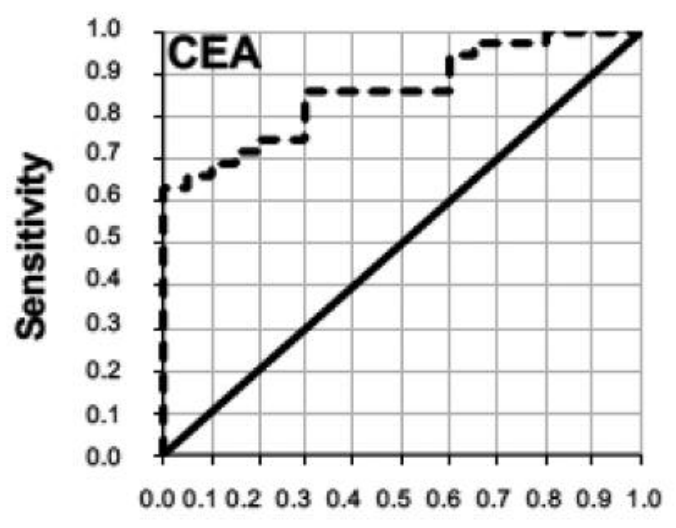

1-Specificity

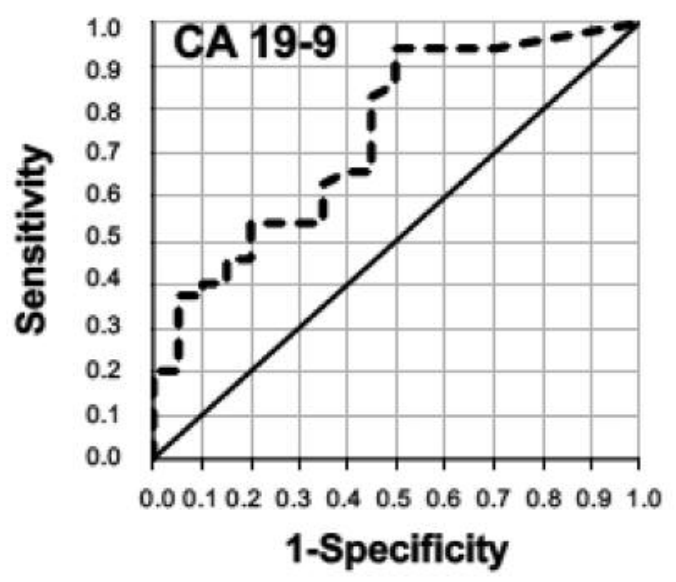

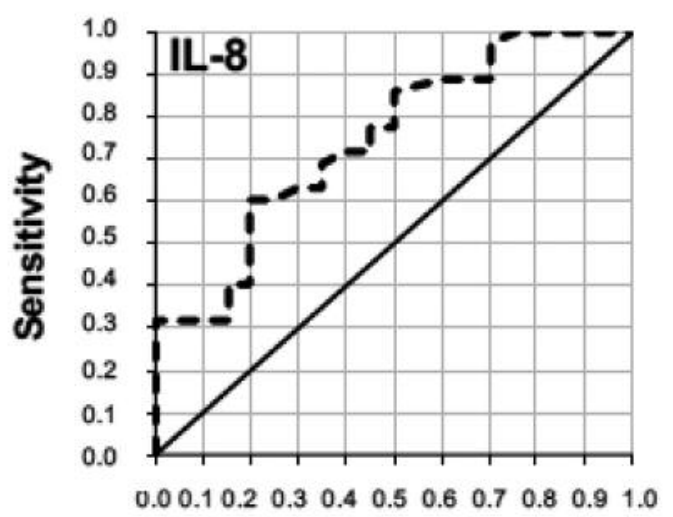

1-Specificity

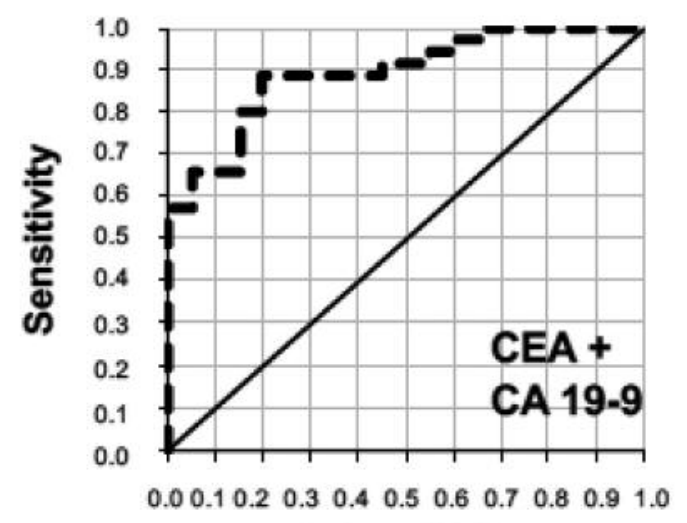

1-Specificity

Figure 3. Receiver operating characteristic (ROC) curves indicate best discriminating markers for comparison of patients with colorectal cancer and benign colorectal diseases. Single markers with best discrimination between benign and malignant colorectal diseases were CEA (area under the curve=AUC 0.859), IL-8 (AUC 0.74) and CA 19-9 (AUC 0.74). Combination of CEA and CA 19-9 improved diagnostic AUC to 0.893.

Table III. Discriminative power between non-metastatic (MO) and metastatic (M1) colorectal cancers.

\begin{tabular}{|c|c|c|c|c|c|c|c|c|c|c|}
\hline & \multicolumn{10}{|c|}{ Tumor markers } \\
\hline & CEA & AFP & CA $15-3$ & CA 19-9 & CA 125 & CYFRA 21-1 & b-HCG & HE4 & OPN & Prolactin \\
\hline \multirow[t]{3}{*}{ M0 vs. M1 } & 0.0001 & 0.7931 & 0.9306 & 0.0161 & 0.0074 & 0.0009 & 0.9815 & 0.4028 & 0.0231 & 0.0067 \\
\hline & \multicolumn{3}{|c|}{ Apoptosis markers } & \multicolumn{3}{|c|}{ Angiogenesis marker } & & & & \\
\hline & $\begin{array}{c}\text { sFas } \\
\mathbf{0 . 0 0 0 7}\end{array}$ & $\begin{array}{c}\mathrm{sFasL} \\
0.4483\end{array}$ & $\begin{array}{l}\text { TRAIL } \\
0.4227\end{array}$ & & $\begin{array}{l}\text { VEGF } \\
0.3162\end{array}$ & & & & & \\
\hline \multicolumn{11}{|c|}{ Immunological markers } \\
\hline M0 vs. M1 & $\begin{array}{c}\text { IL-6 } \\
0.3961\end{array}$ & $\begin{array}{c}\text { IL-8 } \\
\text { 0.0084 }\end{array}$ & $\begin{array}{c}\text { TNFa } \\
0.2107\end{array}$ & $\begin{array}{c}\text { TGFa } \\
0.1820\end{array}$ & $\begin{array}{c}\text { FGF2 } \\
0.7058\end{array}$ & $\begin{array}{c}\text { MIF } \\
0.4586\end{array}$ & $\begin{array}{l}\text { Leptin } \\
0.8047\end{array}$ & $\begin{array}{c}\text { HGF } \\
0.2158\end{array}$ & $\begin{array}{c}\text { SCF } \\
0.1866\end{array}$ & \\
\hline
\end{tabular}

$p$-Values indicate the discriminating power of measured parameters between the subgroups of non-metastatic (M0) and metastatic (M1) colorectal cancers. Significant differences $(p<0.001)$ are highlighted in bold. Nonetheless, markers showing values between 0.05 and 0.001 are also highlighted (bold and italics). 
providing a comprehensive picture of biochemical processes. In a previous study, the methodical and pre-analytical accuracy of included markers was demonstrated which is an essential basis for further clinical testing (36).

In the present clinical assessment, significantly higher levels, not only of markers associated with colorectal cancer such as CEA and CA 19-9, but also of other oncological biomarkers like CA 125, AFP, CYFRA 21-1 and HGF, as well as of cell death and immunological markers sFas, TNF $\alpha$, TGF $\alpha$, OPN, and IL-8 were observed when compared to healthy controls. For apoptotic markers sFas and MIF, this issue has already been discussed (37). These results are quite remarkable as the pattern of these markers may help in the early detection of malignant lesions. However, most levels of TNF $\alpha$, TGF $\alpha$, IL-8, B-HCG, HE4, sFasL, VEGF, IL-6, and FGF-2 were close to the level of quantification; as imprecision was higher in this low value range, clinical results of these markers have to be interpreted with care.

Many immunologic and cell death markers were found in benign colorectal diseases too, as already seen in breast cancer (38). In consequence, there is no discrimination between benign and malignant colorectal diseases which would be most relevant for differential diagnosis. Only CEA, IL-8 and partly CA 19-9 demonstrated discriminatory potential achieving AUCs of $0.859,0.744$ and 0.740 in ROC curves and sensitivities of $65.7 \%, 31.4 \%$ and $37.1 \%$ at $95 \%$ specificity. The combination of CEA and CA 19-9 resulted in an improved AUC of 0.893. Additionally, CYFRA 21-1, CA 125 , OPN and CA 15-3 showed a promising trend for discrimination.

The high accuracy of CEA for detection of colorectal cancer is in line with earlier studies supporting the clinical validity of the multiplex immunoassay (39). In accordance with reports from other studies, CA 19-9 is less sensitive than CEA for colorectal cancer detection. However, it has considerable prognostic impact, particularly in advanced cancer stages $(16,40,41)$. The high diagnostic sensitivity of IL-8 is a new finding that is backed by some preliminary earlier reports. Bălăşoiu et al. described a significant increase of IL-8 levels in the supernatant of tumor cells as well as in serum of cancer patients with higher values in advanced tumor stages (42). In addition, elevated IL-8 levels in patients with liver metastases were found to be associated with worse disease-free and overall survival (43). This is in concordance with stage dependency observed in our cohort.

Although present only at low levels in patient sera, CYFRA 21-1 showed some discriminative power which is in line with earlier studies (44). This may be explained by the fact that cytokeratins are not only general tumor markers for epithelial cancers but also biomarkers of cell death (22) that are released in cases of enhanced cellular turnover. As part of a biomarker panel with CEA, seprase, OPN, ferritin and anti-p53, sensitivity for early colorectal cancer detection was improved to $69.6 \%$ at $95 \%$ specificity and $58.7 \%$ at $98 \%$ specificity as compared to $43.9 \%$ at $95 \%$ specificity for CEA alone (19). As a limitation of the present study, CYFRA 21-1 was found to be a critical parameter in the initial methodical analyses (36) and has to be interpreted with caution. While CA 125 is often used as tumor marker in ovarian cancer, it is elevated in the sera of patients with adenocarcinoma of other sites (14) as well as in patients with peritoneal or pleural effusions, with liver dysfunctions or renal failure (45). Similarly, elevated CA 15-3 levels cannot only be observed in serum of breast cancer but also in patients with adenocarcinoma of other sites up to a certain extent, explaining a potential utility of being included in biomarker panels for detection of colorectal cancer $(14,46$, 47). OPN is described to promote invasiveness as well as progression of colorectal cancer $(48,49)$ and has shown some diagnostic potential $(50,51)$. Furthermore, it has already been included in a multiple biomarker panel leading to promising results (19). Like cytokine markers, TNF $\alpha$, TGF $\alpha$, as well as sFas were not only elevated in colorectal cancer, but also in benign colorectal diseases. In addition, sFas showed a clear stage dependency in colorectal cancer. This is in line with other studies that found higher sFas levels in patients with advanced tumors, poor differentiation, tumor invasion (52) and in metastatic colorectal cancer (53).

According the recommendations of the European Group on Tumor Markers (EGTM) (54) serum samples from all diagnostically-relevant groups, i.e. patients with colorectal cancer, healthy controls and patients with benign colorectal diseases were included in the present study. Blood samples were collected following predefined standards of transport, handling and storage in the Biofluid Biobank Bonn. Prior to testing on its relevance for colorectal cancer detection, the multiplex immunoassay was rigorously checked on its methodical performance and on conceivably influencing preanalytical factors (36). Measurements were performed by trained staff and quality controls were run with every test: Artificial materials and physiological serum pools were used to control interassay precision; benign, malignant and healthy samples were randomly distributed on the same plates to avoid uncontrolled variances. Statistical evaluation was done independently from analytical processes and results were corrected for multiple testing according Bonferroni. As the study was planned as a pilot study using a new multiplex immunoassay, the number of patients was limited in all groups and will have to be validated by further studies.

Although the assay is only available as research use only (RUO) assay it enables the parallel assessment of various biomarker classes relevant to cancer development and progression. Many oncological, cell death and immunological markers showed promising potential for the discrimination between colorectal cancer patients and healthy controls. However, the relevant differentiation of patients with 
malignant and benign colorectal diseases was only achieved by the already established biomarker CEA and CA 19-9 as well as by the newly-identified IL- 8 .

\section{Conclusion}

The newly-available multiplex cancer biomarker panel provides great potential for research approaches when a multitude of biomarkers mirroring different pathophysiological processes of cancer development has to be tested on its clinical utility. Compared to single ELISA tests, multiplexing enables a faster, more cost-efficient and less volume consuming assessment of a considerable number of analytes at the same time. In our setting, the combination of CEA and CA 19-9 showed the best performance in colorectal cancer diagnostic and IL-8 was identified as further valuable marker. Thus, this pilot study presents a robust basis for further validation studies.

\section{Acknowledgements}

This work is part of the MD thesis of Katja Dressen. We acknowledge the excellent technical assistance of Mrs Makbule Kobilay and Mrs Sara Molitor as well as the staff of the Biofluid Biobank of the University Bonn.

\section{References}

1 Ferlay J, Steliarova-Foucher E, Lortet-Tieulent J, Rosso S, Coebergh JW, Comber H, Forman D and Bray F: Cancer incidence and mortality patterns in Europe: estimates for 40 countries in 2012. Eur J Cancer 49: 1374-1403, 2013.

2 Howlader N: SEER Cancer Statistics Review. http:// seer.cancer.gov.

3 Maurel J, Grávalos C, Rivera F, Vera R and González Flores E: SEOM clinical guidelines for the adjuvant treatment of colorectal cancer 2013. Clin Transl Oncol 15: 991-995, 2013.

4 Siegel R, DeSantis C and Jemal A: Colorectal cancer statistics, 2014. CA Cancer J Clin 64: 104-117, 2014.

5 Siegel R, DeSantis C, Virgo K, Stein K, Mariotto A, Smith T, Cooper D, Gansler T, Lerro C, Fedewa S, Lin C, Leach C, Cannady RS, Cho H, Scoppa S, Hachey M, Kirch R, Jemal A and Ward E: Cancer treatment and survivorship statistics, 2012. CA Cancer J Clin 62: 220-241, 2012.

6 Brenner H, Stock C and Hoffmeister M: Effect of screening sigmoidoscopy and screening colonoscopy on colorectal cancer incidence and mortality: systematic review and meta-analysis of randomised controlled trials and observational studies. Brit Med J 348: g2467, 2014.

7 Brenner $\mathrm{H}$ and Hoffmeister M: Colorectal cancer screening: evidence and implementation. Bundesgesundheitsbl 57: 302-306, 2014.

8 Park DI, Ryu S, Kim Y, Lee S, Lee CK, Eun CS and Han DS: Comparison of guaiac-based and quantitative immunochemical fecal occult blood testing in a population at average risk undergoing colorectal cancer screening. Am J Gastroenterol 105: 2017-2025, 2010
9 Sieg A and Friedrich K: Perspectives of colorectal cancer screening in Germany 2009. World J Gastrointest Endosc 1: 12$-16,2009$.

10 Sieverding M, Matterne U, Ciccarello L and Haug U: Colonoscopy use in a country with a long-standing colorectal cancer screening programme: evidence from a large German survey. Z Gastroenterol 48: 1351-1357, 2010.

11 Duffy M, van Dalen A, Haglund C, Hansson L, Holinski-Feder E, Klapdor R, Lamerz R, Peltomaki P, Sturgeon C and Topolcan O: Tumor markers in colorectal cancer: European Group on Tumour Markers (EGTM) guidelines for clinical use. Eur J Cancer 43: 1348-1360, 2007.

12 Lansdorp-Vogelaar I, Knudsen $\mathrm{AB}$ and Brenner H: Costeffectiveness of colorectal cancer screening. Epidemiol Rev 33: 88-100, 2011.

13 Bosetti C, Levi F, Rosato V, Bertuccio P, Lucchini F, Negri E and La Vecchia C: Recent trends in colorectal cancer mortality in Europe. Int J Cancer 129: 180-191, 2011.

14 Stieber P and Heinemann V: Sensible use of tumor markers. J Lab Med 32: 339-360, 2008.

15 Gold P and Freedman SO: Demonstration of tumor-specific antigens in human colonic carcinomata by immunological tolerance and absorption techniques. J Exp Med 121: 439-462, 1965.

16 Sturgeon CM, Duffy MJ, Stenman U, Lilja H, Brunner N, Chan DW, Babaian R, Bast RC Jr, Dowell B, Esteva FJ, Haglund C, Harbeck N, Hayes DF, Holten-Andersen M, Klee GG, Lamerz R, Looijenga LH, Molina R, Nielsen HJ, Rittenhouse H, Semjonow A, Shih IeM, Sibley P, Sölétormos G, Stephan C, Sokoll L, Hoffman BR and Diamandis EP: National Academy of Clinical Biochemistry laboratory medicine practice guidelines for use of tumor markers in testicular, prostate, colorectal, breast, and ovarian cancers. Clin Chem 54: e11-e79, 2008.

17 Duffy MJ, Lamerz R, Haglund C, Nicolini A, Kalousová M, Holubec L and Sturgeon C: Tumor markers in colorectal cancer, gastric cancer and gastrointestinal stromal cancers: European group on tumor markers 2014 guidelines update. Int J Cancer 134: 2513-2522, 2014

18 Brand RE, Nolen BM, Zeh HJ, Allen PJ, Eloubeidi MA, Goldberg M, Elton E, Arnoletti JP, Christein JD, Vickers SM, Langmead CJ, Landsittel DP, Whitcomb DC, Grizzle WE and Lokshin AE: Serum biomarker panels for the detection of pancreatic cancer. Clin Cancer Res 17: 805-816, 2011.

19 Wild N, Andres H, Rollinger W, Krause F, Dilba P, Tacke M and Karl J: A combination of serum markers for the early detection of colorectal cancer. Clin Cancer Res 16: 6111-6121, 2010.

20 Kim Y, Bae SM, Lim H, Kim YJ, Ahn WS and Perez-Gracia JL: Development of multiplexed bead-based immunoassays for the detection of early stage ovarian cancer using a combination of serum biomarkers. PLoS ONE 7: e44960, 2012.

21 Hanahan D and Weinberg RA: Hallmarks of cancer: the next generation. Cell 144: 646-674, 2011.

22 Holdenrieder S and Stieber P: Circulating apoptotic markers in the management of non-small cell lung cancer. Cancer Biomark 6: 197-210, 2010.

23 Kellar KL and Douglass JP: Multiplexed microsphere-based flow cytometric immunoassays for human cytokines. J Immunol Methods 279: 277-285, 2003.

24 Galli C, Basso D and Plebani M: CA 19-9: handle with care. Clin Chem Lab Med 51: 1369-1383, 2013. 
25 Ramaswamy M, Cleland SY, Cruz AC and Siegel RM: Many checkpoints on the road to cell death: regulation of Fas-FasL interactions and Fas signaling in peripheral immune responses. Results Probl Cell Differ 49: 17-47, 2009.

26 Fulda S: Tumor-necrosis-factor-related apoptosis-inducing ligand (TRAIL). Adv Exp Med Biol 818: 167-180, 2014.

27 McMahon G: VEGF receptor signaling in tumor angiogenesis. Oncologist 5(S1): 3-10, 2000.

28 Mroczko B and Szmitkowski M: Hematopoietic cytokines as tumor markers. Clin Chem Lab Med 42: 1347-1354, 2004.

29 Taniguchi K and Karin M: IL-6 and related cytokines as the critical lynchpins between inflammation and cancer. Semin Immunol 26: 54-74, 2014.

30 Zarogoulidis P, Katsikogianni F, Tsiouda T, Sakkas A, Katsikogiannis $\mathrm{N}$ and Zarogoulidis $\mathrm{K}$. Interleukin-8 and interleukin-17 for cancer. Cancer Invest 32: 197-205, 2014.

31 Grieb G, Merk M, Bernhagen J and Bucala R: Macrophage migration inhibitory factor (MIF): a promising biomarker. Drug News Perspect 23: 257-264, 2010.

32 Balkwill F: Tumour necrosis factor and cancer. Nat Rev Cancer 9: 361-371, 2009

33 Ellington AA, Kullo IJ, Bailey KR and Klee GG: Antibodybased protein multiplex platforms: technical and operational challenges. Clin Chem 56: 186-193, 2010.

34 Chowdhury F, Williams A and Johnson P: Validation and comparison of two multiplex technologies, Luminex and Mesoscale Discovery, for human cytokine profiling. J Immunol Methods 340: 55-64, 2009.

35 Dupont NC, Wang K, Wadhwa PD, Culhane JF and Nelson EL: Validation and comparison of luminex multiplex cytokine analysis kits with ELISA: determina-tions of a panel of nine cytokines in clinical sample culture supernatants. J Reprod Immunol 66: 175-191, 2005.

36 Hermann N, Dressen K, Schildberg FA, Jakobs C and Holdenrieder S: Methodical and pre-analytical characteristics of a multiplex cancer biomarker immunoassay. World J Methodol 4: 219-231, 2014

37 Dressen K, Hermann N, Manekeller S, Walgenbach-Bruenagel G, Schildberg FA, Hettwer K, Uhlig S, Kalff JC and Holdenrieder S: Apoptosis-related biomarkers in patients with gastrointestinal cancer. Int J Clin Pharmacol Ther 53: 10621064, 2015.

38 Hermann N, Dressen K, Schroeder L, Debald M, Schildberg FA, Walgenbach-Bruenagel G, Schildberg FA, Hettwer K, Uhlig S, Kuhn W, Hartmann G and Holdenrieder S: Diagnostic relevance of a novel multiplex immunoassay biomarker panel in patients with breast cancer. Tumor Biol 2017: in press.

39 Nielsen HJ, Brünner N, Jorgensen LN, Olsen J, Rahr HB, Thygesen K, Hoyer U, Laurberg S, Stieber P, Blankenstein MA, Davis G, Dowell BL, Christensen IJ: Plasma TIMP-1 and CEA in detection of primary colorectal cancer: a prospective, population based study of 4509 high-risk individuals. Scand J Gastroenterol 46: 60-69, 2011.

40 Hofmann D, Nagel D, Lau-Werner U, Wichmann MW, Hornung $\mathrm{H}$, Stenman UH and Stieber P: Prognosis in non-metastatic colorectal cancer: Multivariate evaluation of preoperative levels of six tumor markers in addition to clinical parameters J Lab Med 31: 76-85, 2007.

41 Reiter W, Stieber P, Reuter C, Nagel D, Lau-Werner U and Lamerz R: Multivariate analysis of the prognostic value of CEA and CA 19-9 serum levels in colorectal cancer. Anticancer Res 20: 5195-5198, 2000 .

42 Bălăşoiu M, Bălăşoiu AT, Mogoantă SŞ, Bărbălan A, Stepan AE, Ciurea RN, Alexandru DO, Enescu A and Mogoantă L: Serum and tumor microenvironment IL-8 values in different stages of colorectal cancer. Rom J Morphol Embryol 55: 575-578, 2014.

43 Hamilton TD, Leugner D, Kopciuk K, Dixon E, Sutherland FR and Bathe OF: Identification of prognostic inflammatory factors in colorectal liver metastases. BMC Cancer 14: 542, 2014.

44 Holdenrieder S, Stieber P, Liska V, Treska V, Topolcan O, Dreslerova J, Matejka VM, Finek J and Holubec L: Cytokeratin serum biomarkers in patients with colorectal cancer. Anticancer Res 32: 1971-1976, 2012.

45 Trapé J, Filella X, Alsina-Donadeu M, Juan-Pereira L, BoschFerrer Á and Rigo-Bonnin R: Increased plasma concentrations of tumour markers in the absence of neoplasia. Clin Chem Lab Med 49: 1605-1620, 2011.

46 Pedersen JW, Gentry-Maharaj A, Nøstdal A, Fourkala E, Dawnay A, Burnell M, Zaikin A, Burchell J, Papadimitriou JT, Clausen H, Jacobs I, Menon U and Wandall HH: Cancerassociated autoantibodies to MUC1 and MUC4--a blinded casecontrol study of colorectal cancer in UK collaborative trial of ovarian cancer screening. Int J Cancer 134: 2180-2188, 2014.

47 Pedersen JW, Blixt O, Bennett EP, Tarp MA, Dar I, Mandel U, Poulsen SS, Pedersen AE, Rasmussen S, Jess P, Clausen H and Wandall HH: Seromic profiling of colorectal cancer patients with novel glycopeptide microarray. Int J Cancer 128: 1860-1871, 2011.

48 Irby RB, McCarthy SM and Yeatman TJ: Osteopontin regulates multiple functions contributing to human colon cancer development and progression. Clin Exp Metast 21: 515-523, 2004.

49 Agrawal D, Agrawal D, Chen T, Irby R, Quackenbush J, Chambers AF, Szabo M, Cantor A, Coppola D and Yeatman TJ: Osteopontin identified as lead marker of colon cancer progression, using pooled sample expression profiling. Cancer Spectrum Knowledge Environ 94: 513-521, 2002.

50 Fedarko NS, Jain A, Karadag A, van Eman MR and Fisher LW: Elevated serum bone sialoprotein and osteopontin in colon, breast, prostate, and lung cancer. Clin Cancer Res 7: 4060-4066, 2001.

51 Fan Y, Zhang X, Yang Z, Sun X, Li S, Zhong L, Cheng X, Wang $Y$ and Ma YR: The polymorphisms of osteopontin gene and plasma osteopontin protein levels with susceptibility to colorectal carcinoma. DNA Cell Biol 32: 594-600, 2013.

52 Abbasova SG, Vysotskii MM, Ovchinnikova LK, Obusheva MN, Digaeva MA, Britvin TA, Bahoeva KA, Karabekova ZK, Kazantzeva IA, Mamedov UR, Manuchin IB and Davidov MI: Cancer and soluble Fas. Bull Exp Biol Med 148: 638-642, 2009.

53 Kushlinskii NE, Britvin TA, Abbasova SG, Perevoshchikov AG, Prorokov VV, Kostanyan IA, Knysh VI and Lipkin VM: Soluble Fas antigen in the serum of patients with colon cancer. Bull Exp Biol Med 131: 361-363, 2001.

54 Anonymous: Tumour markers in gastrointestinal cancers--EGTM recommendations. European Group on Tumour Markers. Anticancer Res 19: 2811-2815, 1999.

Received March 18, 2017

Revised April 4, 2017

Accepted April 7, 2017 